\title{
Room temperature hydrogen sensors based on metal decorated $\mathrm{WO}_{3}$ nanowires
}

\author{
Jarmo Kukkola a,*, Melinda Mohl a , Anne-Riikka Leino ${ }^{a}$, Jani Mäklin a , Niina Halonen ${ }^{a}$, \\ Andrey Shchukarev ${ }^{\mathrm{b}}$, Zoltan Konya ${ }^{\mathrm{c}}$, Heli Jantunen ${ }^{\mathrm{a}}$, Krisztian Kordas ${ }^{\mathrm{a}}$ \\ a Microelectronics and Materials Physics Laboratories, Department of Electrical Engineering, University of Oulu, P.O. Box 4500, FI-90014, Finland \\ ${ }^{\mathrm{b}}$ Department of Chemistry, Chemical-Biological Center, Umeå University, SE-90187 Umeå, Sweden \\ c Department of Applied and Environmental Chemistry and MTA-SZTE Reaction, Kinetics and Surface Chemistry Research Group, University of Szeged, \\ Rerrich, B. ter 1, H-6720 Szeged, Hungary
}

\section{A R T I C L E I N F O}

\section{Article history:}

Received 17 December 2012

Received in revised form 10 May 2013

Accepted 24 May 2013

Available online $\mathrm{xxx}$

\section{Keywords:}

Metal oxide

Tungsten oxide

Gas sensor

Hydrogen sensor

Nanowire

\begin{abstract}
A B S T R A C T
The emerging hydrogen economy has created a demand for the development of improved hydrogen sensors operating at room temperature. In this work, we present hydrogen detectors based on metal decorated $\mathrm{WO}_{3}$ nanowires that were able to detect $1000 \mathrm{ppm}$ of $\mathrm{H}_{2}$, even at room temperature $\left(30^{\circ} \mathrm{C}\right)$, with relatively short recovery time and high sensitivity. The nanowires were synthesized by a hydrothermal process and decorated with $\mathrm{PdO}$ and $\mathrm{PtO}_{x}$ nanoparticles by decomposition of $\mathrm{Pd}(\mathrm{acac})_{2}$ and $\mathrm{Pt}(\mathrm{acac})_{2}$ precursors. The gas responses were tested for $\mathrm{H}_{2}, \mathrm{NO}, \mathrm{H}_{2} \mathrm{~S}$ and $\mathrm{CO}$ analyte gases in an air buffer at 150,200 and $250^{\circ} \mathrm{C}\left(\mathrm{H}_{2}\right.$ also at 30,70 and $\left.130^{\circ} \mathrm{C}\right)$.
\end{abstract}

(c) 2013 Elsevier B.V. All rights reserved.

\section{Introduction}

Commercial hydrogen gas sensors are already utilized in hydrogen powered transport, fire alarms, process and flue gas analyzers, and leakage detectors. Such devices must meet strict specifications related to performance, lifetime, reliability and cost. Sensing of hydrogen is based on a number of different physical/chemical phenomena related to, e.g. the change in thermal/electrical conductivity, work function, mechanical properties but even optical/acoustic methods may be applied [1-5].

In resistive gas sensing devices, such as the ones discussed in this work, gaseous analytes are causing local polarization in the solid (i.e. redistributing the local charge carriers) upon adsorption [6]. The change of the local electrical field is screened by the carriers, and will vanish after some distance, called the Debye length [7]. If the diameter or thickness of the particles, wires or films is sufficiently low, the adsorbed molecules are influencing the whole volume of the solid thus inducing significant change in the electrical transport behavior [6]. Accordingly, smaller particles suggest better gas sensing. However, one should also take into account the increasing number of contacts and the superposition of the

\footnotetext{
* Corresponding author. Tel.: +358 294487973.

E-mail address: jarmo.kukkola@ee.oulu.fi (J. Kukkola).
}

corresponding contact resistances between the nanoparticles in the percolation path [6]. Therefore, there is an optimal size for the particles. In order to maximize the gas sensor response, at least one dimension of the sensing particles should be about twice the Debye length $L_{D}=\left[\varepsilon_{0} \varepsilon_{r} k_{B} T /\left(q^{2} n\right)\right]^{1 / 2}$, where $\varepsilon_{0}$ is the vacuum permittivity, $\varepsilon_{r}$ is the dielectric permittivity, $k_{B}$ is the Boltzmann constant, $T$ is the temperature, $q$ is the elementary charge and $n$ is the carrier concentration [8]. The carrier concentration is dependent on the type and the crystal structure of the material as well as on the concentration of defects and impurities present in the lattice. Carrier concentration in tungsten oxides has been evaluated to be from $10^{23}$ to $10^{25} \mathrm{~m}^{-3}$ [9-13] with a corresponding DC dielectric permittivity of $\sim 20$ [14]. Based on these values, the optimum crystal size $2 L_{D}$ is between 4 and $40 \mathrm{~nm}$ (at $500 \mathrm{~K}$ ), which is similar to the conclusion of a previous study [15].

Tungsten oxide nanowires were first prepared about 10 years ago [16] and since then have been considered as promising functional materials for catalytic/sensing [17-22], photocatalytic [23], electrocatalytic [24], electrochomic [25], gasochromic [26] and field-emission devices [27]. Due to the unique properties caused by the large surface area/volume ratio, synthesis methods of one dimensional tungsten oxide structures have been studied extensively. Solvo-/hydrothermal [28,29], sol-gel [22], template-assisted [30], electrospinning [17], and various physical [31-35] and chemical vapor deposition [36] methods have been presented. 
In this work, the gas sensing characteristics of hydrothermally processed $\mathrm{WO}_{3}$ nanowires decorated with $\mathrm{PdO}$ or $\mathrm{PtO}_{x}$ nanoparticles are discussed. Most of the work is focused on evaluating the sensitivity of the prepared sensors: $S=\left(G-G_{0}\right) /\left(G_{0} c\right) \times 100 \%$, where $G$ and $G_{0}$ are the conductance of the sensor before and after gas exposure, respectively, and $c$ is the gas concentration. Gas sensors based on nanowire networks are expected to deliver higher stability over devices with nanoparticles of a similar diameter. The more pronounced tendency for sintering of nanoparticles at elevated operating temperatures is favoring the use of nanowires [37]. In addition, nanowires enable percolation between the metal electrodes with fewer contacts than in the case of nanoparticles. Durability over bulk Pd/Pt based sensors is also expected due to the lack of continuous Pd/Pt films that crack under repeated hydrogen exposures. The prepared nanowires have relatively small crystallites to optimize the responses to gas exposures. Also short response and recovery times are expected due to short diffusion paths of gases to the surfaces of loosely packed nanowires. The prepared sensors were observed to compete [19] and even outperform previously studied tungsten oxide nanowire sensors decorated with Pd or Pt in terms of sensitivity to hydrogen at room temperature [20,21].

\section{Experimental}

Pristine tungsten oxide nanowires were synthesized by the hydrothermal method described elsewhere [38,39]. In brief, sodium-tungstate $(2.5 \mathrm{~g})$ and sodium-sulfate $(3.0 \mathrm{~g})$ were dissolved in distilled water $(80 \mathrm{ml})$, then hydrochloric acid $(4.5 \mathrm{ml}, 3 \mathrm{M})$ was added drop-wise under continuous stirring. After $10 \mathrm{~min}$ of stirring the mixture was transferred into a Teflon-lined stainless steel autoclave and was kept at $180^{\circ} \mathrm{C}$ for $48 \mathrm{~h}$. The product (i.e. $\mathrm{WO}_{3}$ nanowires) was collected by centrifugation, washed with distilled water and ethanol, and finally dried at $60^{\circ} \mathrm{C}$ in air. To decorate the surface with $\mathrm{PdO}$ or $\mathrm{PtO}_{x}$ nanoparticles, $\left.28.6 \mathrm{mg} \mathrm{Pd(acac}\right)_{2}$ or $20.2 \mathrm{mg} \mathrm{Pt}(\mathrm{acac})_{2}$ was dissolved in $100 \mathrm{ml}$ acetone followed by dispersion of $1.0 \mathrm{~g}$ of the prepared $\mathrm{WO}_{3}$ by $3 \mathrm{~h}$ of ultrasonic agitation and $6 \mathrm{~h}$ of magnetic stirring. The solvent was evaporated at $80^{\circ} \mathrm{C}$ in an $\mathrm{N}_{2}$ atmosphere, while stirring the mixture. The product was annealed at $300^{\circ} \mathrm{C}$ in air for $2 \mathrm{~h} .3 .2 \pm 0.1 \mathrm{mg}$ of the obtained $\mathrm{WO}_{3}$, $\mathrm{WO}_{3}-\mathrm{PdO}$ and $\mathrm{WO}_{3}-\mathrm{PtO}_{x}$ nanowires were dispersed in deionized water of $1.0 \pm 0.1 \mathrm{ml}$ by ultrasonic agitation $(5 \mathrm{~min})$. Five droplets of the dispersions were drop cast $(\sim 3 \mu$ l of each) over the Pt electrode fingers of the $\mathrm{Si} / \mathrm{SiO}_{2}$ substrates while keeping the substrate temperature at $90^{\circ} \mathrm{C}$ to allow for quick drying. Each droplet was dried before depositing the subsequent one. As a result, a dense, light gray film of the nanowires formed over and between the electrodes. Before inserting into the gas chamber, the prepared devices were allowed to dry overnight at room temperature.

The microstructure of the samples was studied by energy filtered transmission electron microscopy (EFTEM, Leo 912 Omega) and field-emission scanning electron microscopy (FESEM, Zeiss ULTRA plus). The crystal structure was examined by X-ray diffraction (XRD, Siemens D5000, $\mathrm{Cu} \mathrm{K} \alpha$ radiation). The analysis of the chemical composition and the oxidation states was carried out by X-ray photoelectron spectroscopy (XPS, Kratos Axis Ultra DLD, monochromated $\mathrm{Al} \mathrm{K \alpha}$ source, analysis area of $0.3 \mathrm{~mm} \times 0.7 \mathrm{~mm}$, applying a charge neutralizer).

Gas response measurements were performed in a Linkam THMS600 heating and freezing stage connected to an Agilent 3458A multimeter and a pre-mixing gas blender controlled by a computer. The sensitivities of the prepared gas sensors were studied in the following order for $\mathrm{NO}, \mathrm{H}_{2}, \mathrm{CO}$, and $\mathrm{CH}_{4}$ (at 150,200 and $250^{\circ} \mathrm{C}$ ) and finally for $\mathrm{H}_{2}$ (at 30,70 and $130^{\circ} \mathrm{C}$ ) analytes in a dry synthetic air buffer at $5 \mathrm{~V}$ of constant bias. Before each gas measurement, a 2-h temperature pulse of $250^{\circ} \mathrm{C}$ in synthetic air was applied to clean the sensors' surfaces. Sensors were heated and cooled at $10^{\circ} \mathrm{C} / \mathrm{min}$ during the gas measurements. Note: In this paper, $30^{\circ} \mathrm{C}$ is considered as the room temperature, because it can be easily kept constant in our measurement setup. The real room temperature is fluctuating and cannot be maintained without additional cooling.

\section{Results and discussion}

Particles of size $4.9 \pm 2.1 \mathrm{~nm}(\mathrm{PdO})$ and $2.5 \pm 1.9 \mathrm{~nm}\left(\mathrm{PtO}_{x}\right)$ were formed on the surface of the $\mathrm{WO}_{3}$ nanowires after the decomposition of their acetylacetonate precursors (Fig. 1). At least partly due to their smaller diameter, $\mathrm{PtO}_{x}$ nanoparticles were observed to
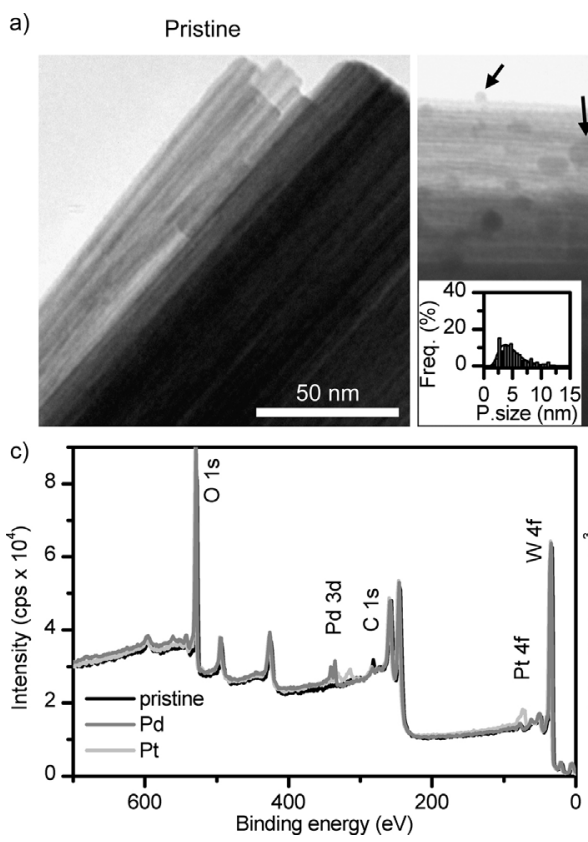

$\mathrm{Pd}$

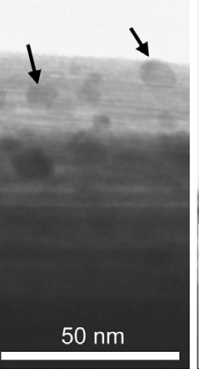

Pt
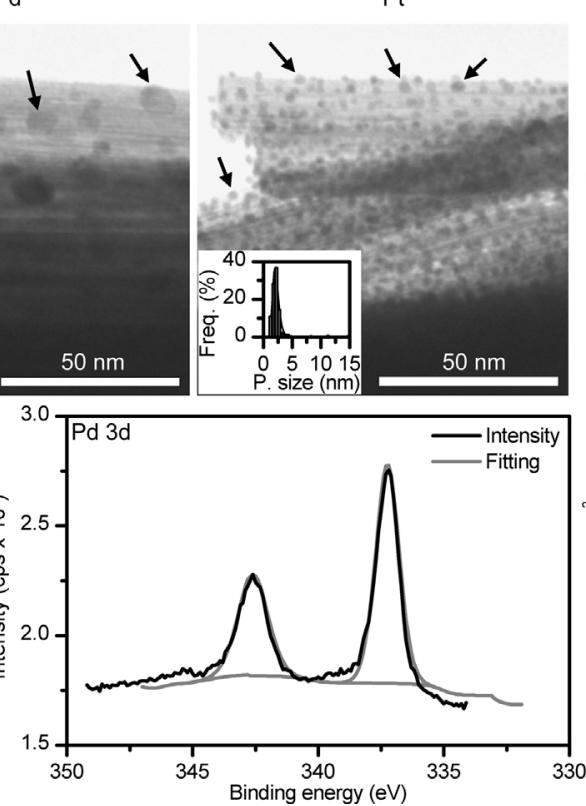

b)
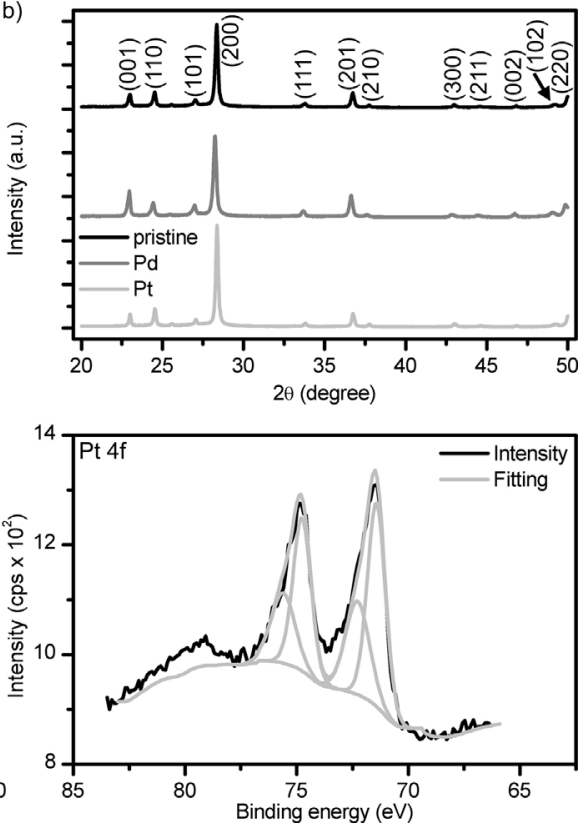

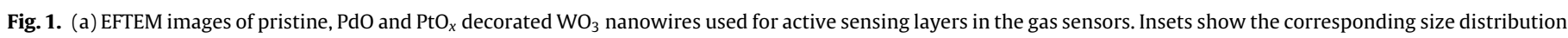
diagrams of the decorating nanoparticles. (b) XRD patterns and (c) X-ray photoelectron spectra of pristine and decorated $\mathrm{WO}_{3}$ nanowires. 

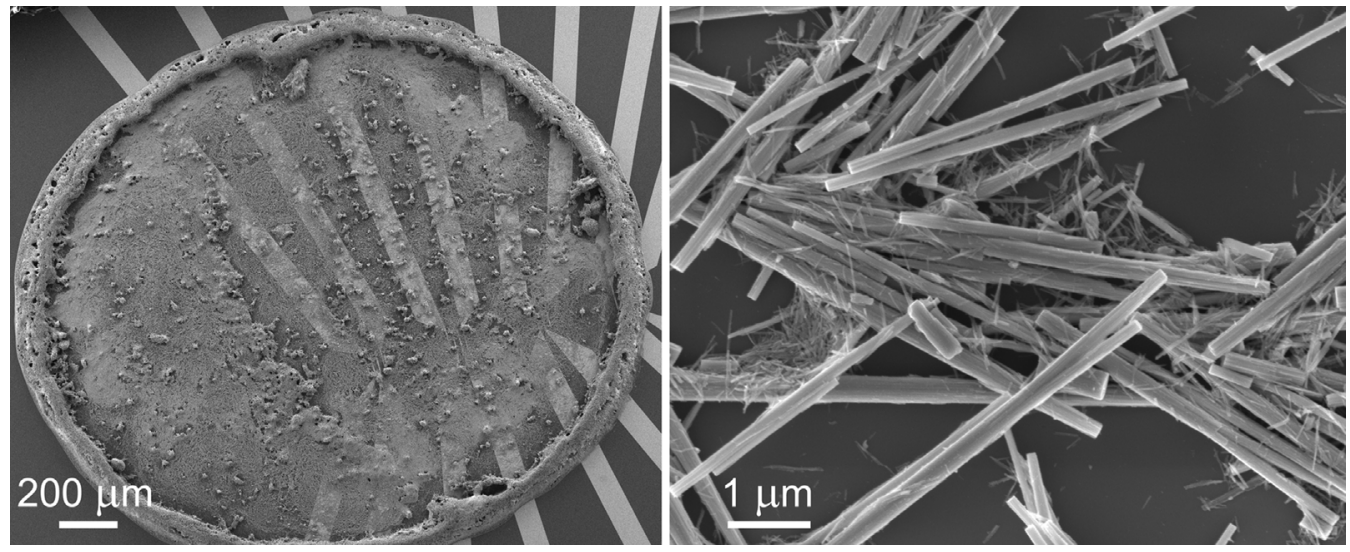

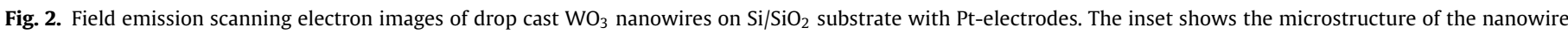
network in the middle of the droplet.

cover the surface of the $\mathrm{WO}_{3}$ nanowires more uniformly than the PdO nanoparticles.

Based on XRD analysis, the nanowires are hexagonal $\mathrm{WO}_{3}$ with an average crystal diameter of $38 \pm 5 \mathrm{~nm}$ as calculated from the broadening of (110), (101), (200), (201) and (111) reflections. Almost identical XRD patterns were obtained for the pristine and the metal decorated samples (Fig. 1b), i.e. the analysis failed to uncover the reduced, or the oxide phases of the decorating particles (could be caused by their small size, low concentration and/or amorphous structure).

Results of X-ray photoelectron spectroscopy (Fig. 1c) indicate the nanoparticles in the Pd-modified sample are PdO rather than metallic Pd (binding energy of $\mathrm{Pd} 3 \mathrm{~d}_{5 / 2}$ peak at $337.3 \mathrm{eV}$ ). In the case of the Pt modified $\mathrm{WO}_{3}$, both the metallic and oxide phases are present ( $P t 4 f_{7 / 2}$ peak positions at 71.4 and $72.3 \mathrm{eV}$ ).

The prepared gas sensors are based on modulation of the resistance of the $\mathrm{WO}_{3}$ nanowires that fill the gaps and percolate between the Pt electrodes. Dried $\mathrm{WO}_{3}$ nanowire droplets have a thick outer border caused by a common coffee ring effect [40,41], while in the middle section, a tangled but thinner layer of the nanowires forms (Fig. 2). Based on FESEM and EFTEM micrographs, the diameter of the nanowires has relatively large variation from $\sim 20$ to $\sim 200 \mathrm{~nm}$. Relating this to the XRD peak broadening results, we concluded that in the dried powders, not only individual crystallites but also bundles of nanowires are present.

At all temperatures and concentrations, the response of the pristine nanowires to hydrogen was relatively low compared to the decorated samples (Fig. 3), while the response of all samples to $\mathrm{NO}, \mathrm{CO}$ and $\mathrm{CH}_{4}$ was moderate (see supplementary material). At the optimal operation temperature of the $\mathrm{PdO}$ and the $\mathrm{PtO}_{x} \mathrm{dec}$ orated nanowire based sensors, the sensitivity values after $5 \mathrm{~min}$ of $1000 \mathrm{ppm} \mathrm{H}_{2}$ exposure are as high as $140 \pm 70 \% / \mathrm{ppm}$ (at $200{ }^{\circ} \mathrm{C}$ ) and $24 \pm 5 \% / \mathrm{ppm}$ (at $250^{\circ} \mathrm{C}$ ) respectively, as seen in Fig. 5 . For the pristine nanowires, this figure is $0.3 \pm 0.3 \% / \mathrm{ppm}$ (at $250^{\circ} \mathrm{C}$ ), which is consistent with the results in our earlier article on nanoparticle based sensors [42]. The high response of the $\mathrm{PdO}$ and the $\mathrm{PtO}_{x}$ decorated sensors is related to the partial reduction of the particles and the dissociation of $\mathrm{H}_{2}$ on metal nanoparticles followed by a spill-over onto the $\mathrm{WO}_{3}$ surface [43]. The supposed surface reduction of the $\mathrm{PdO}$ and the $\mathrm{PtO}_{x}$ nanoparticles, along with the initial pulses of $\mathrm{H}_{2}$, seems to be supported by the lower sensitivity of the devices upon the very first injections of $10 \mathrm{ppm} \mathrm{H}_{2}$ compared to the subsequent $10 \mathrm{ppm}_{2}$ pulses.

Since the sensor response toward $\mathrm{H}_{2}$ was still very large, even at $150^{\circ} \mathrm{C}$, we have performed further measurements at 30,70 and $130^{\circ} \mathrm{C}$ to see whether the devices could be used without external

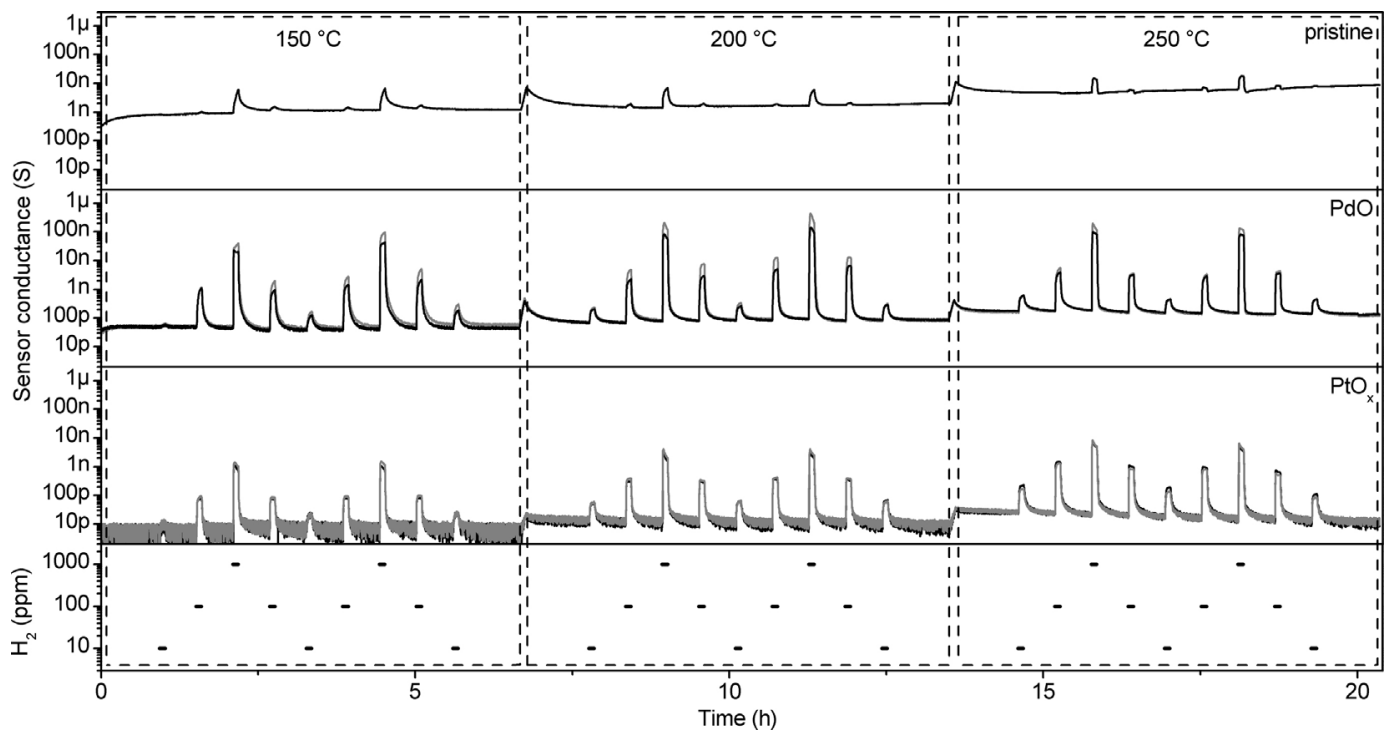

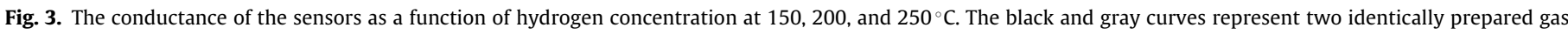
sensing devices. Please note the curves are partially overlapping thus the otherwise similar noise levels are not clearly visible for the black curves. 


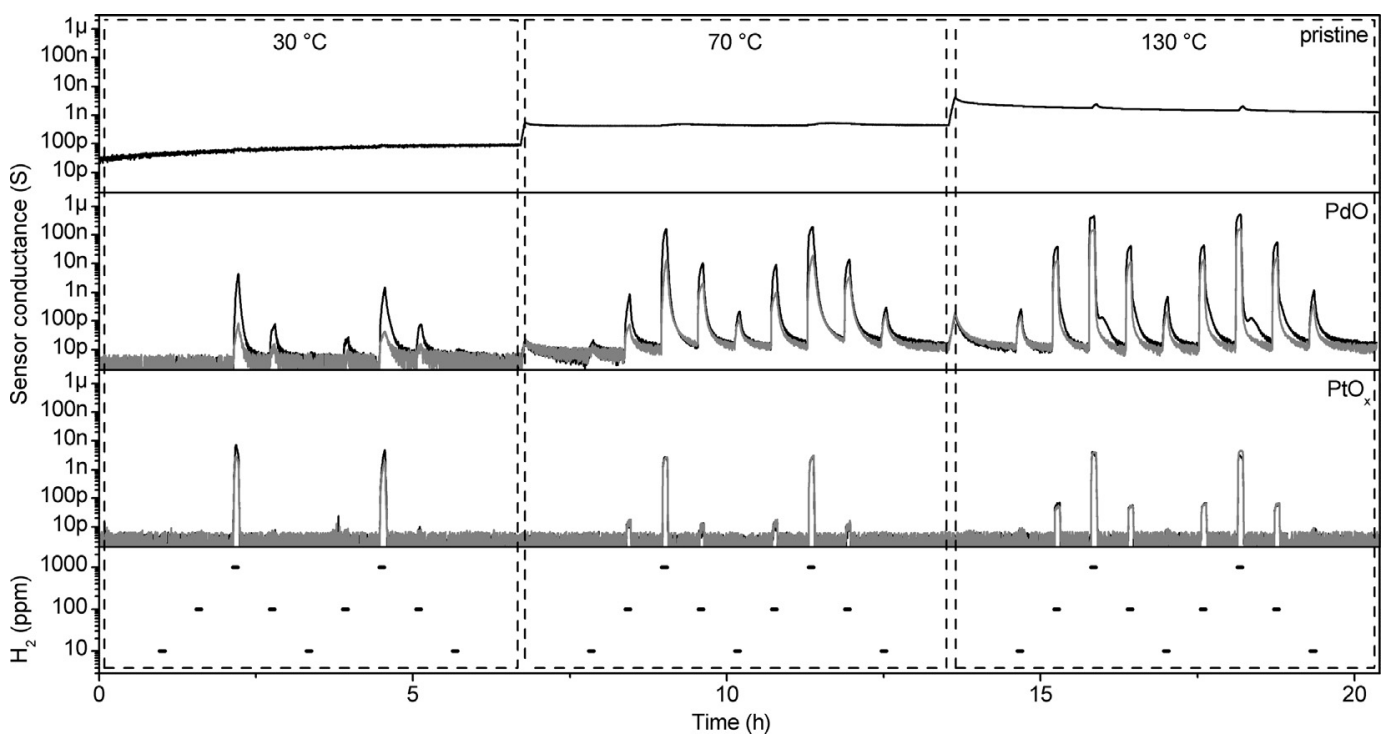

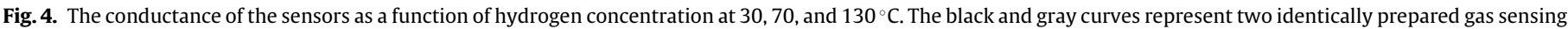
devices. Please note the curves are partially overlapping thus the otherwise similar noise levels are not clearly visible for the black curves.
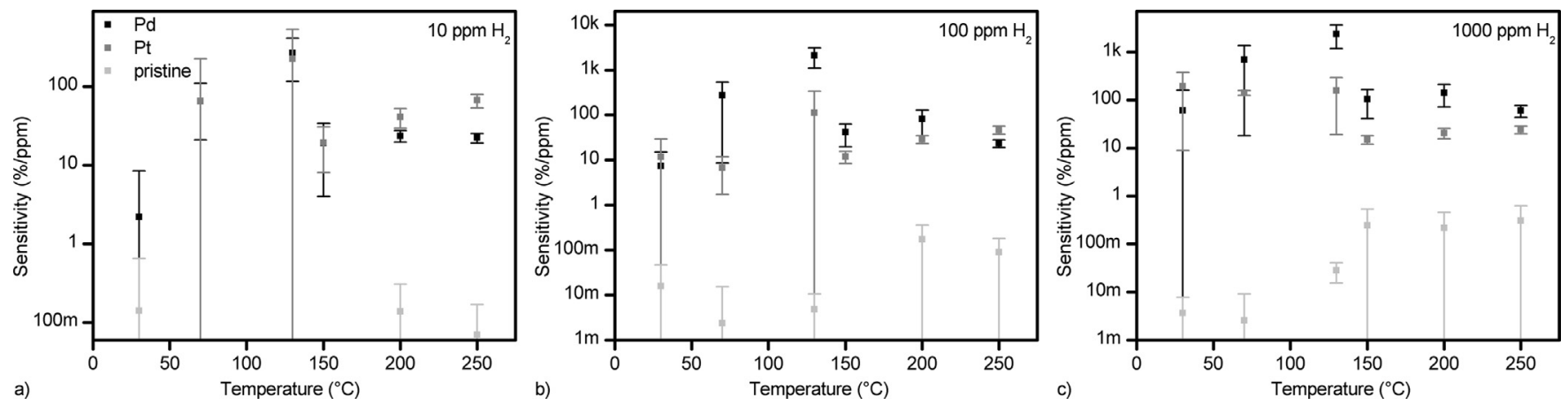

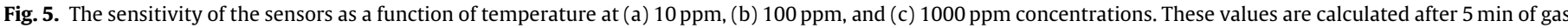
exposure. It should be noted that the conductance is further increasing, even after $1 \mathrm{~h}$ of gas exposure, as seen in Fig. B1 of the supplementary material.

heating. Although the pristine $\mathrm{WO}_{3}$ nanowires failed to detect $\mathrm{H}_{2}$ at room temperature $\left(30^{\circ} \mathrm{C}\right)$, both the $\mathrm{PdO}$ and the $\mathrm{PtO}_{x}$ decorated samples showed excellent response for $1000 \mathrm{ppm} \mathrm{H}_{2}$ (Fig. 4) compared to sol-gel processed $\mathrm{WO}_{3} / \mathrm{Pd}[44]$ or $\mathrm{WO}_{3} / \mathrm{Pt}$ [45] thin film hydrogen sensors reported by other groups. Whilst a significant response caused by the $\mathrm{H}_{2}$ gas was seen, the conductance did not stabilize even during very long, (up to $1 \mathrm{~h}$ ), gas pulses at 30 and $70^{\circ} \mathrm{C}$ (Fig. B1). The conductance was increasing almost linearly as a function of time during the gas exposure. As concluded earlier for porous $\mathrm{WO}_{3}$ films [46] hydrogen molecules dissociate to hydrogen atoms that spill-over to $\mathrm{WO}_{3}$ surface and bind to surface oxygen of the lattice thus forming water molecules. Desorption of these water molecules remove oxygen and hence create oxygen vacancies, which diffuse to the interior of the crystal. Accordingly, the slow response time of our sensors (similar to gasochromic coloration of $\mathrm{WO}_{3}$ described in Ref. [46]) is explained by the slow diffusion of oxygen vacancies and also slow desorption of water from the tungsten oxide surface. The recovery time constant of the $\mathrm{Pt}$ and Pd decorated samples was observed to be less than 10 and 15 min, respectively, at $30^{\circ} \mathrm{C}$.

Even though, many of the nanowires used in this work (Figs. 1 and 2) appear to have larger diameter $(20-200 \mathrm{~nm}$ ) than the optimum (4-40 nm) for resistive gas sensing applications, the sensors show an extraordinary increase of conductance upon exposure to $\mathrm{H}_{2}$. One reason can be a good percolation of thin nanowires (i.e. those that are ideal) between the electrodes. In a random network of thin (ideal) and thick (less ideal) nanowires, the change of conductance in the thicker nanowires is not expected to influence the gas sensitivity as much as the thin nanowires provided these latter ones are percolated. On the other hand, according to the EFTEM micrographs (Fig. 1), the larger nanowires seem to be consisting of smaller crystals, which could possibly also contribute to the large conductivity modulation caused by $\mathrm{H}_{2}$.

\section{Conclusions}

Hexagonal tungsten oxide nanowires decorated with PdO or $\mathrm{PtO}_{x}$ nanoparticles proved to be excellent materials for detecting $\mathrm{H}_{2}$ gas with very high sensitivity and good selectivity in contrast to the $\mathrm{NO}, \mathrm{CO}$ and $\mathrm{CH}_{4}$ analytes. Both decoration types resulted in very similar sensor performances. The conductance of the decorated nanowire sensor devices was found to increase with up to five orders of magnitude when exposed to $1000 \mathrm{ppm}$ of $\mathrm{H}_{2}$ in air, even at room temperature. Both types of decorated sensors had long response times (conductance is almost a linear function of time), though the recovery slopes could be fitted well with exponential decay curves of a $\sim 10 \mathrm{~min}$ time constant. The overall power consumption of the devices is very low. Without the presence of $\mathrm{H}_{2}$, there is practically no current through the device and therefore the power consumption is almost zero. When $\mathrm{H}_{2}$ molecules are present, the peak power consumption at $30^{\circ} \mathrm{C}$ is $P=U^{2} S=(5 \mathrm{~V})^{2} \times 10 \mu \mathrm{S}=250 \mu \mathrm{W}$. Accordingly, the device could be 
operated reasonably well from an ordinary battery-type power source, and thus the decorated $\mathrm{WO}_{3}$ nanowires reported here are attractive materials for gas sensing elements in a number of different devices, such as portable low power consumption hydrogen leakage detectors, autonomous sensor assemblies and in fire alarms.

\section{Acknowledgements}

Maria Szabó (University of Szeged) is acknowledged for the synthesis of the pristine nanowires. The financial support of TEKES (Autosys, Prindemo-POC, Imphona projects) and the Academy of Finland (Rocaname) are acknowledged. J.K. acknowledges INFOTECH Oulu Graduate School, Riitta and Jorma J. Takanen, Tauno Tönning and the Emil Aaltonen Foundation for financial support for the work. Z.K. acknowledges the support of the TÁMOP-4.2.2.A11/1/KONV-2012-0047 project.

\section{Appendix A. Supplementary data}

Supplementary data associated with this article can be found, in the online version, at http://dx.doi.org/10.1016/j.snb.2013.05.082.

\section{References}

[1] T. Hübert, L. Boon-Brett, G. Black, U. Banach, Hydrogen sensors - a review, Sensors and Actuators B: Chemical 157 (2011) 329-352.

[2] W.J. Buttner, M.B. Post, R. Burgess, C. Rivkin, An overview of hydrogen safety sensors and requirements, International Journal of Hydrogen Energy 36 (2011) 2462-2470.

[3] C. Christofides, A. Mandelis, Solid state sensors for trace hydrogen gas detection, Journal of Applied Physics 68 (1990) R1-R30.

[4] H. Gu, Z. Wang, Y. Hu, Hydrogen gas sensors based on semiconductor oxide nanostructures, Sensors 12 (2012) 5517-5550.

[5] K. Gleeson, E. Lewis, Response changes of thin film palladium based optical fibre hydrogen sensors over time, Journal of Physics: Conference Series 76 (2007), 012004(1-6).

[6] N. Barsan, U. Weimar, Conduction model of metal oxide gas sensors, Journal of Electroceramics 7 (2001) 143-167.

[7] R.L. Murray, Nuclear Energy: An Introduction to the Concepts, Systems, and Applications of Nuclear Processes, 6th ed., Elsevier Inc., Burlington, 2009, pp. 201.

[8] H.Czichos, T. Saito, L. Smith (Eds.), Springer Handbook of Metrology and Testing, Springer, Heidelberg, Dordrecht, London, New York, 2001.

[9] K.J. Patel, C.J. Panchal, V.A. Kheral, M.S. Desai, Growth, structural, electrical and optical properties of the thermally evaporated tungsten trioxide $\left(\mathrm{WO}_{3}\right)$ thin films, Materials Chemistry and Physics 114 (2009) 475-478.

[10] P.S. Patil, P.R. Patil, E.A. Ennaoui, Characterization of ultrasonic spray pyrolyzed tungsten oxide thin films, Thin Solid Films 370 (2000) 38-44.

[11] H. Rui, Z. Jing, Y. Rong, Synthesis and electrical characterization of tungsten oxide nanowires, Chinese Physics B 18 (2009) 3024-3030.

[12] M. Regragui, V. Jousseaume, M. Addou, A. Outzourhit, J.C. Bernéde, B. El Idrissi, Electrical and optical properties of $\mathrm{WO}_{3}$ thin films, Thin Solid Films 397 (2001) 238-243.

[13] K.H. Yoon, C.W. Shin, D.H. Kang, Photoelectrochemical conversion in a $\mathrm{WO}_{3}$ coated p-Si photoelectrode: effect of annealing temperature, Journal of Applied Physics 81 (1997) 7024-7029.

[14] J.B. Goodenough, A. Hamnett, G. Huber, F. Hulliger, M. Leib, S.K. Ramasesha, H. Werheit, Landolt-Bornstein: Numerical Data and Functional Relationships in Science and Technology, New series Group III, Volume 17, Semiconductors Subvolume g, Physics of Non-Tetrahedrally Bonded Binary Compounds III, Springer-Verlag, Heidelberg, 1984, pp. 289.

[15] J. Tamaki, Z. Zhang, K. Fujimori, M. Akiyama, T. Harada, N. Miura, N. Yamazoe, Grain-size effects in tungsten oxide-based sensor for nitrogen oxides, Journal of the Electrochemical Society 141 (1994) 2207-2210.

[16] G. Gu, B. Zheng, W.Q. Han, S. Roth, J. Liu, Tungsten oxide nanowires on tungsten substrates, Nano Letters 8 (2002) 849-851.

[17] K.M. Sawicka, A.K. Prasad, P.I. Gouma, Metal oxide nanowires for use in chemical sensing applications, Sensor Letters 3 (2005) 31-35.

[18] D. Meng, N.M. Shaalan, T. Yamazaki, T. Kikuta, Preparation of tungsten oxide nanowires and their application to $\mathrm{NO}_{2}$ sensing, Sensors and Actuators B: Chemical 169 (2012) 113-120.

[19] J. Choi, J. Kim, Highly sensitive hydrogen sensor based on suspended, functionalized single tungsten nanowire bridge, Sensors and Actuators B: Chemical 136 (2009) 92-98.

[20] O. Garcia-Serrano, O. Goiz, F. Chavez, G. Romero-Parades, R. Pena-Sierra, Pddecorated $\mathrm{ZnO}$ and $\mathrm{WO}_{3}$ nanowires for sensing applications, in: Proceedings of the IEEE Sensors Conference, 2011, pp. 998-1001.
[21] L.F. Zhu, J.C. She, J.Y. Luo, S.Z. Deng, J. Chen, N.S. Xu, Study of physical and chemical processes of $\mathrm{H}_{2}$ sensing of Pt-coated $\mathrm{WO}_{3}$ nanowire films, Journal of Physical Chemistry C 114 (2010) 15504-15509.

[22] C.-L. Dai, M.-C. Liu, F.-S. Chen, C.-C. Wu, M.-W. Chang, A nanowire $\mathrm{WO}_{3}$ humidity sensor integrated with micro-heater and inverting amplifier circuit on chip manufactured using CMOS-MEMS technique, Sensors and Actuators B: Chemical 123 (2007) 896-901.

[23] X.Z. Li, F.B. Li, C.L. Yang, W.K. Ge, Photocatalytic activity of $\mathrm{WO}_{\mathrm{x}}-\mathrm{TiO}_{2}$ under visible light irradiation, Journal of Photochemistry and Photobiology A: Chemistry 141 (2001) 209-217.

[24] X. Cui, L. Guo, F. Cui, Q. He, J. Shi, Electrocatalytic activity and CO tolerance properties of mesostructured $\mathrm{Pt} / \mathrm{WO}_{3}$ composite as an anode catalyst for PEMFCs, Journal of Physical Chemistry C 113 (2009) 4134-4138.

[25] C.-C. Liao, F.-R. Chen, J.-J. Kai, $\mathrm{WO}_{3-x}$ nanowires based electrochromic devices, Solar Energy Materials and Solar Cells 90 (2006) 1147-1155.

[26] J.Y. Luo, S.Z. Deng, Y.T. Tao, F.L. Zhao, L.F. Zhu, L. Gong, J. Chen, N.S. Xu, Evidence of localized water molecules and their role in the gasochromic effect of $\mathrm{WO}_{3}$ nanowire films, Journal of Physical Chemistry C 113 (2009) 15877-15881.

[27] Y. Li, Y. Bando, D. Goldberg, Quasi-aligned single-crystalline $\mathrm{W}_{18} \mathrm{O}_{49}$ nanotubes and nanowires, Advanced Materials 15 (2003) 1294-1296.

[28] S.J. Yoo, J.W. Lim, Y.-E. Sung, Y.H. Jung, H.G. Choi, D.K. Kim, Fast switchable electrochromic properties of tungsten oxide nanowire bundles, Applied Physics Letters 90 (2007), 173126(1-3).

[29] J. Su, X. Feng, J.D. Sloppy, L. Guo, C.A. Grimes, Vertically aligned $\mathrm{WO}_{3}$ nanowire arrays grown directly on transparent conducting oxide coated glass: synthesis and photoelectrochemical properties, Nano Letters 11 (2011) 203-208.

[30] K. Zhu, H. He, S. Xie, X. Zhang, W. Zhou, S. Jin, B. Yue, Crystalline $\mathrm{WO}_{3}$ nanowires synthesized by templating method, Chemical Physics Letters 377 (2003) 317-321.

[31] J. Zhou, Y. Ding, S.Z. Deng, L. Gong, N.S. Xu, Z.L. Wang, Three-dimensional tungsten oxide nanowire networks, Advanced Materials 17 (2005) 2107-2110.

[32] A. Ponzoni, V. Russo, A. Bailini, C.S. Casari, M. Ferroni, A. Li Bassi, A. Migliori, V. Morandi, L. Ortolani, G. Sberveglieri, C.E. Bottani, Structural and gas-sensing characterization of tungsten oxide nanorods and nanoparticles, Sensors and Actuators B: Chemical 153 (2011) 340-346.

[33] L.-J. Chou, M.-T. Chang, Y.-L. Chueh, J.J. Kim, H.S. Park, D. Shindo, Electron holography for improved measurement of microfields in nanoelectrode assemblies, Applied Physics Letters 89 (2006), 023112(1-3).

[34] K.Q. Hong, M.H. Xie, H.S. Wu, Tungsten oxide nanowires synthesized by a catalyst-free method at low temperature, Nanotechnology 17 (2006) 4830-4833.

[35] Y.B. Li, Y. Bando, D. Goldberg, K. Kurashima, $\mathrm{WO}_{3}$ nanorods/nanobelts synthesized via physical vapor deposition process, Chemical Physics Letters 367 (2003) 214-218

[36] C. Klinke, J.B. Hannon, L. Gignac, K. Reuter, P. Avouris, Tungsten oxide nanowire growth by chemically induced strain, Journal of Physical Chemistry B 109 (2005) 17787-17790.

[37] G. Korotcenkov, B.K. Cho, Instability of metal oxide-based conductometric gas sensors and approaches to stability improvement (short survey), Sensors and Actuators B: Chemical 156 (2011) 527-538.

[38] X.C. Song, Y.F. Zheng, E. Yang, Y. Wang, Large-scale hydrothermal synthesis of $\mathrm{WO}_{3}$ nanowires in the presence of $\mathrm{K}_{2} \mathrm{SO}_{4}$, Materials Letters 61 (2007) 3904-3908.

[39] M. Szabó, Diploma thesis, University of Szeged, Hungary, 2011.

[40] D. Soltman, V.Subramanian, Inkjet-printed line morphologies and temperature control of the coffee ring effect, Langmuir 24 (2008) 2224-2231.

[41] X. Shen, C.-M. Ho, T.-S. Wong, Minimal size of coffee ring structure, Journal of Physical Chemistry B 114 (2010) 5269-5274.

[42] J. Kukkola, et al., Inkjet-printed gas sensors: metal decorated $\mathrm{WO}_{3}$ nanoparticles and their gas sensing properties, Journal of Materials Chemistry 22 (2012) $17878-17886$.

[43] S.J. Ippolito, S. Kandasamy, K. Kalantar-Zadeh, W. Wlodarski, Layered SAW hydrogen sensor with modified tungsten trioxide selective layer, Sensors and Actuators B: Chemical 108 (2005) 553-557.

[44] S. Fardindoost, A. Iraji zad, F. Rahimi, R. Ghasempour, Pd doped $\mathrm{WO}_{3}$ films prepared by sol-gel process for hydrogen sensing, International Journal of Hydrogen Energy 35 (2010) 854-860.

[45] H. Nakagawa, N. Yamamoto, S. Okazaki, T. Chinzei, S. Asakura, A room temperature operated hydrogen leak sensor, Sensors and Actuators B: Chemical 93 (2003) 468-474.

[46] A. Georg, W. Graf, N.V. Wittwer, Mechanism of the gasochromic coloration of porous $\mathrm{WO}_{3}$ films, Solid State Ionics 127 (2000) 319-328.

\section{Biographies}

Jarmo Kukkola received his M.Sc. in theoretical physics from the University of Oulu, Finland, in 2008. He is currently a Ph.D. student at the Microelectronics and Materials Physics Laboratories, University of Oulu. His research interest is the electrical properties of nanostructured materials.

Melinda Mohl born in 1982, graduated with an M.Sc. in environmental chemistry (2006, University of Szeged, Hungary) and a Ph.D. in nanotechnology (2011, Univ. Szeged). She undertook her internship at The Facultés Universitaires Notre-Dame de la Paix in Namur (Belgium) in 2005-2006. In autumn 2011, she commenced as 
a postdoctoral research fellow at the University of Oulu, Finland. Previously, she has also worked on porous metal nanostructures and carbon nanotube based sensors at Rice University, USA. Her current research interest is focused on developing nanostructures for (photo)catalysis, sensors and electronic devices.

Anne-Riikka Leino born in 1985, graduated with an M.Sc. in Organic Chemistry (2010, University of Oulu, Finland). In 2009, she joined the Microelectronics and Materials Physics Laboratories as a research assistant. Since 2010, she is pursuing studies toward her Ph.D. with the topic of nanoparticle formation and agglomeration over nanostructured surfaces.

Jani Mäklin graduated as an electrical engineer at the Department of Electrical and Information Engineering, University of Oulu, Finland, in 2010. Since 2006, he has been working as a research assistant in EU and Tekes projects aiming at sensor applications of nanostructured materials. Currently, he is pursuing research toward his doctoral degree in microelectronics with emphasis on gas sensors.

Niina Halonen received her M.Sc. in organic chemistry from the University of Oulu, Finland, in 2006. In the same year, she joined the Microelectronics and Materials Physics Laboratories, University of Oulu, and started postgraduate studies. Since 2007, she is also a member of the National Graduate School in Nanoscience. Her expertise is in thin and thick film technologies, optical lithography and carbon nanotube synthesis/applications.

Andrey Shchukarev, M.Sc. in chemistry (Leningrad State University, Russia, 1979), Ph.D. in inorganic chemistry (Leningrad State University, Russia, 1983) and Docent in chemistry (Umeå University, Sweden, 2009), is working as a researcher and assistant professor at the Environmental and Biogeochemistry Group, Department of Chemistry, University of Umeå. His research interest is the development of surface analysis techniques, in particular XPS, and their application to real environmental, biological and biomedical objects.

Zoltan Konya was born in Hungary in 1971, graduated with an M.Sc. in chemistry (1994, University of Szeged, Hungary) and Ph.D. in chemistry (1998, University of Szeged, Hungary). He is professor of chemistry and since 2010, he is head of the Applied and Environmental Chemistry Department of the University of Szeged, Hungary. Dr. Kónya has published 200+ papers in refereed scientific journals and co-authored 10 book chapters. He holds 10 national and international patents. His research interest is the development of new nanostructured materials and their application to real chemical, environmental, biological and biomedical objects.

Heli Jantunen received her M.Sc. in astronomy and physics, Faculty of Sciences in 1982, the Diploma in education in 1985, and an M.Sc. in electrical engineering, Faculty of Technology in 1989, University of Oulu, Finland. After being in industry for 10 years, she joined the Microelectronics and Materials Physics Laboratories, Department of Electrical Engineering in 1999 and received the Dr. Tech. degree in microelectronics (with honors) in 2001. She is professor of technical physics at the University of Oulu, and head of the laboratory and the department. She is chair of the Scientific Advisory Board of Defence (Electronics Group), the Research Council for Natural Sciences and Engineering, Academy of Finland, and the ESF Standing Committee for PESC. Her research is focused on novel sensor and RF applications by implementation of advanced microwave and functional materials, structures and nanotechnology into multifunctional micromodules and printed electronics devices. She has been an invited speaker, session chair and/or scientific committee member of 40 international scientific conferences, and holds over 13 national and international patents. She has $140+$ scientific journal publications ( $>1100$ citations). Her current focus is mainly devoted to her ERC (European Research Council) Advanced Grant project.

Krisztian Kordas was born in Hungary in 1975, graduated with an M.Sc. in physics and chemistry (1998, University of Szeged, Hungary), Dr. Tech. Microelectronics (2002) and Docent of Nanotechnology (2004, University of Oulu, Finland). Between 2004 and 2009, he was appointed as an academy research fellow, by the Academy of Finland. From 2011 until 2012, he was an assistant professor at the Department of Chemistry of the Umeå Univerity. Currently, he is a research professor at the Microelectronics and Materials Physics Laboratories, University of Oulu supervising research projects (EU, TEKES and Academy of Finland) as well as diploma works of students and postgraduate studies of young researchers. Dr. Kordas has published $90+$ papers in refereed scientific journals and co-authored 4 book chapters. His research is focused on synthesis, structural and electrical characterization, and implementation of nanostructured materials for electronics, sensors and (photo)catalyst applications. 